\title{
Use Duration Unit
}

National Cancer Institute

\section{Source}

National Cancer Institute. Use Duration Unit. NCI Thesaurus. Code C82584.

The unit of measure for the duration of substance usage. 